\title{
FUNCTIONAL EXERCISE CAPACITY EVALUATED BY TIMED WALK TESTS IN MYASTHENIA GRAVIS
}

\author{
YELIZ SALCI, PT, PhD, ${ }^{1}$ ECEM KARANFIL, PT, ${ }^{1}$ AYLA Fil BALKAN, PT, ${ }^{1}$ EBRU ÇALIK KÜTÜKÇÜ, PT, ${ }^{1}$ ALi NAIM CEREN, PT, \\ FATMA AYVAT, PT, MSC, ${ }^{1}$ CAN EBRU BEKIRCAN-KURT, MD, ${ }^{2}$ and KADRIYE ARMUTLU, PT $^{1}$ \\ ${ }^{1}$ Department of Physiotherapy and Rehabilitation, Faculty of Health Sciences, Hacettepe University, 06100, Sihhıye, Ankara, Turkey \\ ${ }^{2}$ Department of Neurology, Faculty of Medicine, Hacettepe University, Ankara, Turkey \\ Accepted 11 September 2018
}

\begin{abstract}
Introduction: We sought to evaluate the test-retest reliability and construct validity of the 6- and 2-minute walk tests (6mWT and $2 \mathrm{mWT}$, respectively) in patients with myasthenia gravis (MG). Methods: Thirty-one patients with generalized MG were enrolled in this study. The $6 \mathrm{mWT}, 2 \mathrm{mWT}$, MG-specific quality of life questionnaire Turkish version (MG-QoL15T), quantitative myasthenia gravis test (QMG), and pulmonary function tests were administered. Results: The intraclass correlation coefficients of $2 \mathrm{mWT}$ and $6 \mathrm{mWT}$ were 0.894 and 0.932 , respectively. The $6 \mathrm{mWT}$ and $2 \mathrm{mWT}$ had moderate correlations with forced vital capacity, maximal inspiratory pressure, QMG score, and MG-QoL15T score ( $\rho$ for $6 \mathrm{mWT}$ : $0.579, \quad 0.539,-0.572$, and $-0.474 ; \rho$ for $2 \mathrm{mWT}$ : $0.460,0.446,-0.532,-0.457)$. Both tests had similar performances for predicting disease severity (area under the curve $=0.761$ for $6 \mathrm{mWT}$ and 0.759 for $2 \mathrm{mWT}$ ). Discussion: The 6mWT and 2mWT have excellent test-retest reliability as well as moderate construct validity for the evaluation of functional exercise capacity patients with MG.
\end{abstract}

Muscle Nerve 59:208-212, 2019

Myasthenia gravis (MG) is an autoimmune disease in which both antibody and cellular immunological attacks block nicotinic acetylcholine receptors, muscle-specific tyrosine kinases, and/or other postsynaptic proteins at the postsynaptic neuromuscular junction. ${ }^{1,2}$ Patients with MG may have limited exercise capacity because of proximal muscle weakness, fatigability, and impairment in respiratory muscles. ${ }^{3-5}$ Assessment and follow-up of functional capacity in patients with MG is important for testing new therapeutic approaches or goal setting in rehabilitation. Because of the difficulty of measuring the maximum oxygen consumption in clinical settings and the absence of valid and reliable physical performance tests, there are shortcomings when monitoring the physical performances of patients with MG.

As an alternative to laboratory exercise tests, the 6 -minute walk test $(6 \mathrm{mWT})$ is commonly employed

\footnotetext{
Abbreviations: $2 \mathrm{mWT}, 2$-minute walk test; $6 \mathrm{mWT}, 6$-minute walk test; $A \cup C$, area under the curve; FEV1, forced expiratory volume in the first second; FVC, forced vital capacity; ICC, intraclass correlation coefficient; MEP, maximal expiratory pressure; MG, myasthenia gravis; MGFA, Myasthenia Gravis Foundation of America; MG-QoL15T, myasthenia gravis-specific quality of life questionnaire Turkish version; MIP, maximal inspiratory pressure; QMGS, quantitative myasthenia gravis score; ROC, receiver operating characteristic

Key words: 2-minute walk test, 6-minute walk test, functional exercise capacity, myasthenia gravis, test-retest reliability, validity
}

Conflicts of Interest: The authors declare that they have no conflicts of interest.

Correspondence to: Y. Salcı; e-mail: fztyeliz@hotmail.com

(C) 2018 Wiley Periodicals, Inc.

Published online 19 September 2018 in Wiley Online Library

(wileyonlinelibrary.com). DOI 10.1002/mus.26345 for testing functional exercise capacity. It assesses all of the systems required for exercise and reflects the submaximal level of exercise capacity. ${ }^{6}$ It has been validated in cardiopulmonary disorders and neurological disorders as an exercise capacity test. ${ }^{7-10}$ The 2-minute walk test (2mWT) has also been used as a short-distance walking test. ${ }^{11-14}$

We sought to evaluate the usefulness of the $6 \mathrm{mWT}$ in patients with $\mathrm{MG}$ and to compare it with the $2 \mathrm{mWT}$. We hypothesized that both $6 \mathrm{mWT}$ and $2 \mathrm{mWT}$ have good test-retest reliability and construct validity.

\section{MATERIALS AND METHODS}

Participants. This cross-sectional study was carried out in the Department of Neurological Physiotherapy, Hacettepe University; the Hacettepe University Non-Interventional Clinical Research Ethics Board approved this study (GO 16/814-24). Forty-five patients with MG were enrolled in this study, but only 31 patients met 2 eligibility criteria: (1) age ranging from 18 to 65 years with a diagnosis of MG by a neurologist and (2) generalized symptoms (having score II or III according to the Myasthenia Gravis Foundation of America [MGFA] clinical classification). Patients with comorbid neuromuscular and cardiorespiratory disorders were excluded. All participants signed the written informed consent form and underwent study-related assessments.

\section{Outcome Measurements First Admission.}

Demographic data (age, sex, body mass index) and disease course (time elapsed since the last myasthenic crisis, disease duration and medication history, and comorbid diseases) were recorded. Patients underwent an examination by the physiotherapists, with both performance-based and self-report assessments. The evaluation included quantitative myasthenia gravis score (QMGS), pulmonary function tests, $6 \mathrm{mWT}, 2 \mathrm{mWT}$, and the myasthenia gravis-quality of life questionnaire Turkish version (MG-QoL15T). Timed walk tests were performed at 3-h intervals on the same day and were performed in the same order for all patients ( $6 \mathrm{mWT}$ followed by $2 \mathrm{mWT})$. Patients did not do any practice walk before the first recorded trial. Each timed walk test was conducted approximately $1-2 \mathrm{~h}$ after pyridostigmine intake. Patients were taking $240-360 \mathrm{mg} /$ day pyridostigmine.

Second Admission. Three to 7 days after the first admission, the $6 \mathrm{mWT}$ and $2 \mathrm{mWT}$ were repeated with 3-h intervals in between the 2 tests.

Quantitative Myasthenia Gravis Score. A thirteen-item performance-based scale was used to rate patients' performance from 0 to 3 (total score range 0-39). Higher scores indicate worse function. ${ }^{15}$ 
Pulmonary Function Tests. The spirometry test was performed by a physiotherapist specialist in cardiopulmonary rehabilitation who followed the European Respiratory Society guidelines for using a Fitmate MED spirometer (Cosmed, Rome, Italy). ${ }^{16}$ Forced expiratory volume in the first second (FEV1), vital capacity (VC), forced vital capacity (FVC), and FEV1/FVC were recorded. The highest score among the 3 trials was used.

Respiratory Muscle Strength Tests. Respiratory muscle strength tests were conducted with a portable electronic mouth pressure device ((Micro MPM; Micro Medical, Kent, England). Maximal inspiratory and expiratory pressures (MIP and MEP, respectively) were measured. ${ }^{17}$ The predicted values of MIP and MEP were calculated from the same age- and sexmatched references. ${ }^{18}$ Respiratory muscles were considered as weak if they were less than $60 \%$ of predicted MIP and MEP values. $^{19}$

Timed Walk Tests. Both the $6 \mathrm{mWT}$ and the $2 \mathrm{mWT}$ were performed in a $30-\mathrm{m}$ hallway. The distances traveled were separately recorded within 2 and then $6 \mathrm{~min}$. Patients were asked to rate their fatigue according to the Borg scale before and after the tests. Arterial oxygen saturation also was measured via pulse oximetry (Veron; Shenzhen Aeon Technology, Shenzhen City, Guangdong, China). The American Thoracic Society guidelines were followed for $6 \mathrm{mWT}$ and $2 \mathrm{mWT} .{ }^{6}$ The total distances walked in meters in 6 and 2 min were also calculated as predicted percentages. ${ }^{20,21}$

Myasthenia Gravis-Specific Quality of Life Assessment, Turkish Version. All patients completed the MG-QoL15T at the first admission. ${ }^{22,23}$

Statistical Analysis. Numeric variables were expressed as mean and standard deviation, and categorical variables were expressed as counts. Test-retest reliability and validity analyses were conducted according to the Consensus Based Standards for the Selection of Health Status Measurement Instruments (https://www.cosmin.nl/) guidelines. ${ }^{24}$

Test-retest Reliability. The $6 \mathrm{mWT}$ and the $2 \mathrm{mWT}$ intertest reliabilities were assessed with intraclass correlation coefficient (ICC) analyses.

Table 1. Patient demographic characteristics and disease course

\begin{tabular}{lc} 
Variables & Mean $\pm \mathrm{SD}($ min-max $), \mathrm{n}=31$ \\
\hline Age, $y$ & $47.90 \pm 16.18(18-65)$ \\
BMl, kg/m² & $25.48 \pm 4.70(16.07-36.26)$ \\
Disease duration, y & $6.46 \pm 6.26(1-29)$ \\
QMGS & $8.83 \pm 6.14(0-21)$ \\
Sex, men/women, \% & $51.61 / 48.38$ \\
MGFA, \% & \\
Ila & 12.90 \\
IIb & 45.16 \\
IIla & 16.12 \\
IIlb & 25.80 \\
\hline
\end{tabular}

BMI, body mass index; MGFA, Myasthenia Gravis Foundation America Classification System; min-max, minimum to maximum; QMGS, quantitative myasthenia gravis scale.
Hypothesis Testing. Hypothesis testing was analyzed with Spearman's rank correlation coefficient $(\rho)$ for construct validity. Correlation analyses were performed between 2mWT/6mWT and FVC, MIP, QMGS, and MG-QoL15T. Dancey and Reidy's classification was used to interpret the strength of the correlations: $0.1-0.3=$ weak correlation, 0.4 $0.6=$ moderate correlation, $\geq 0.7=$ strong correlation. ${ }^{25}$

A Bonferroni correction was applied for multiple comparisons. Spearman's correlation was conducted between $6 \mathrm{mWT}$ and 5 variables: $2 \mathrm{mWT}$, FVC, MIP, QMGS, and MG-QoL15T. $P \leq 0.01$ was considered significant $(P \leq 0.05 / 5)$. The same $P$ value was used for correlations between $2 \mathrm{mWT}$ and the 5 variables 6mWT, FVC, MIP, QMGS, and MG-QoL15T.

Predictive Validity. Receiver operating characteristic (ROC) curves and area under the ROC curves (AUC) analyses were used for predictive validity. Patients were divided into 2 groups according to the MGFA clinical classification: (1) IIa and IIb were grouped as 2 and referred to as minimal disability and (2) IIIa and IIIb were grouped as 3 and referred to as moderate disability. Sensitivity and specificity of $6 \mathrm{mWT} / 2 \mathrm{mWT}$ to disease severity was determined.

Power Analysis. A post hoc power analysis was performed in $\mathrm{G}^{*}$ Power 3.0.10 (Heinrich Heine University, Düsseldorf, Germany http://www.gpower.hhu.de/) ${ }^{26}$ Analysis was carried out by using the $6 \mathrm{mWT}$ data (the first trial) with the results of Gibbons et al. ${ }^{27}(\mathrm{~d}=2.237, \alpha=0.05$ [two-tailed] $)$.

\section{RESULTS}

Thirty-one patients with MG were included in the study. No patient prematurely terminated the $6 \mathrm{mWT}$ or the $2 \mathrm{mWT}$ test due to fatigue or dyspnea, and no patient had substantial oxygen desaturation, which is defined as $\geq 4 \%$ decrease in arterial oxygen saturation from baseline. The mean changes in the fatigue perception during the first trials of $6 \mathrm{mWT}$ and $2 \mathrm{mWT}$ were $3.06 \pm 2.15$ and $1.74 \pm 2.09$, respectively. Patient demographic data and disease courses are displayed in Table 1.

Outcome Measurements Pulmonary Function and Strength Test Results. According to the pulmonary function tests, $18(58.06 \%)$ patients showed a restrictive pattern, whereas $13(41.93 \%)$ patients were normal. The median MIP and MEP values were $78 \mathrm{cmH}_{2} \mathrm{O}$ (median predicted $89.32 \%$, interquartile range $72 \%-96 \%$ ) and $85 \mathrm{cmH} 20$ (median predicted $53.11 \%$, interquartile range $36 \%-64 \%$ ), respectively. Twenty-seven (87.09\%) patients had normal MIP values, whereas $8(25.80 \%)$ patients had normal MEP values.

$6 m W T / 2 m W T$ Results. The mean distance traveled during the first $6 \mathrm{mWT}$ trial was $465.17 \pm 86.99 \mathrm{~m}$; this was $79.29 \%$ of the expected value. The mean distance traveled by the patients in the first $2 \mathrm{mWT}$ trial was $170.19 \pm 30.77 \mathrm{~m}$; this was $87.09 \%$ of the expected value. 
Statistical Analysis Outcomes Test-Retest Reliability. There was excellent test-retest reliability for both the $2 \mathrm{mWT}$ and the $6 \mathrm{mWT} \quad(\mathrm{ICC}=0.894$ and 0.932 , respectively). In addition, the ICC values of predicted $2 \mathrm{mWT}$ and $6 \mathrm{mWT}$ were 0.863 and 0.956 , respectively.

Hypothesis Testing. The $2 \mathrm{mWT}$ and $6 \mathrm{mWT}$ tests showed a high correlation $(\rho=0.879)$. The other analyses of construct validity of both tests demonstrated moderate correlation and ranged from 0.446 to 0.579 (Table 2 ).

Predictive validity. According to the AUC values, the $6 \mathrm{mWT}$ and $2 \mathrm{mWT}$ had similar performances for discriminating different levels of disease severity $(\mathrm{AUC}==0.761$ and 0.759 , respectively; Fig. 1 ).

Power analyses. According to the post hoc power analyses, the power of the study (1- $\beta$ ) was $>99 \%$.

\section{DISCussion}

This study has potentially useful findings because both timed walk tests were found to be reliable between test-retest conditions. Moreover, it was found that they had good construct validity. Both timed walk tests presented similar performances for discriminating among different levels of disease severity.

In previous studies, the $6 \mathrm{mWT}$ was shown to be an exercise capacity test in neuromuscular diseases. $^{14,28,29}$ McDonald et $a l^{29}$ found that $6 \mathrm{mWT}$ test-retest reliability was excellent in patients with Duchenne muscular dystrophy. However, modifications were used in this study, such as addition of an orientation video prior to testing, continuous verbal encouragement from the testing staff to maintain attention to the task, or a "safety chaser" to walk behind the participant during testing. We did not require modification. In our study, the tests were performed 1-2 $\mathrm{h}$ after pyridostigmine intake. Pyridostigmine may improve symptoms and maximize both reproducibility and distances traveled during

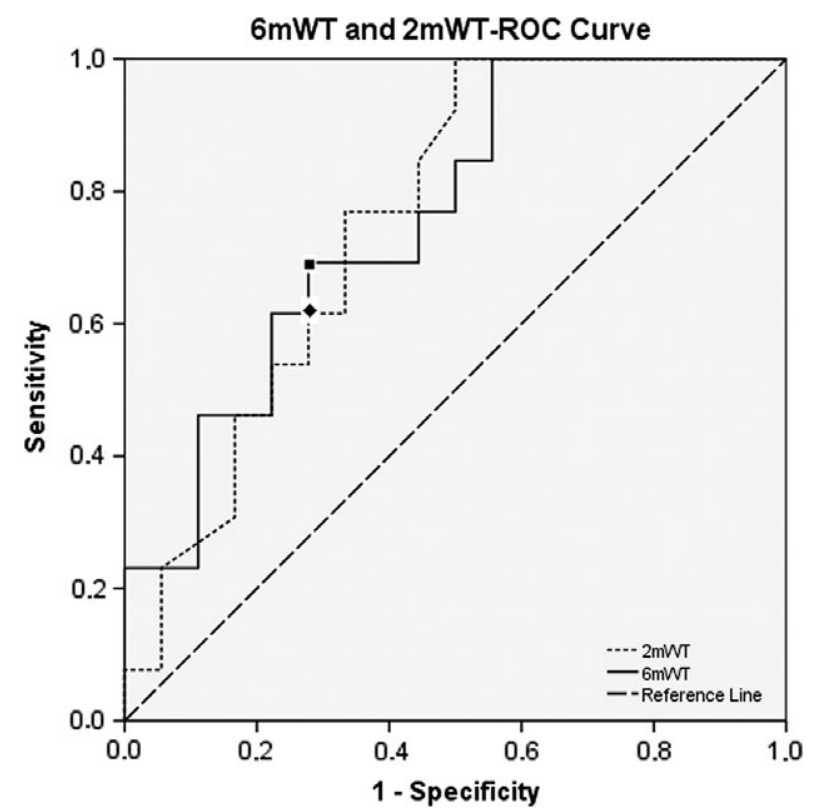

FIGURE 1. Receiver operating characteristic curves for predicting mild vs. moderate disability level. The optimum cutoff point (solid square, -) was $457 \mathrm{~m}$ for $6 \mathrm{mWT}$, with $69.2 \%$ sensitivity and $72.2 \%$ specificity. The optimum cutoff point (solid lozenge, $\downarrow$ ) was $152.5 \mathrm{~m}$ for the $2 \mathrm{mWT}$, with $61.5 \%$ sensitivity and $72.2 \%$ specificity. 2mWT, 2-minute walk test; $6 \mathrm{mWT}$ : 6-minute walk test; $\mathrm{ROC}$, receiver operating characteristic.

the tests. However, reproducibility cannot be directly attributed to pyridostigmine intake unless the 2 conditions (with or without medication) are compared.

The normal values of the mean distance traveled in the $6 \mathrm{mWT}$ have been well defined in previous studies. $^{21,27,30-32}$ Gibbons et al. ${ }^{27}$ reported that the healthy population's normal $6 \mathrm{mWT}$ was $655 \pm 84 \mathrm{~m}$ (in the first and unfamiliar trial) for people in the age range 20-40 years. Furthermore, Troosters et $a l^{30}{ }^{30}$ reported normal values as $631 \pm 93 \mathrm{~m}$ for people in the age range 50-85 years. The age range for patients in our study was $18-65$ years, and the mean distance traveled in the $6 \mathrm{mWT}$ was significantly less than in both healthy young and healthy elderly participants. Likewise, the mean distance traveled by patients with MG in the $2 \mathrm{mWT}$ was less than the

Table 2. Relationship of $2 \mathrm{mWT} / 6 \mathrm{mWT}$ to respiratory function tests, respiratory muscle strength tests, disease severity, and quality of life

\begin{tabular}{|c|c|c|c|c|c|}
\hline Assessment & & $2 \mathrm{mWT}, \mathrm{m}$ & $6 m W T, m$ & FVC, L & MIP, $\mathrm{cmH}_{2} \mathrm{O}$ \\
\hline $2 \mathrm{mWT}, \mathrm{m}$ & $\begin{array}{l}\rho \\
P \text { value }\end{array}$ & $\ldots$ & $\begin{array}{c}0.879 \\
<0.001^{1}\end{array}$ & $\begin{array}{l}0.460 \\
0.009^{1}\end{array}$ & $\begin{array}{l}0.446 \\
0.012\end{array}$ \\
\hline $6 m W T, m$ & $\begin{array}{l}\rho \\
P \text { value }\end{array}$ & $\begin{array}{c}0.879 \\
<0.001^{1}\end{array}$ & $\begin{array}{l}\ldots \\
\ldots\end{array}$ & $\begin{array}{l}0.579 \\
0.001^{1}\end{array}$ & $\begin{array}{c}0.539 \\
0.002^{1}\end{array}$ \\
\hline MG-QoL15T & $\begin{array}{l}\rho \\
P \text { value }\end{array}$ & $\begin{array}{c}-0.457 \\
0.010^{1}\end{array}$ & $\begin{array}{l}-0.474 \\
0.007^{1}\end{array}$ & NS & NS \\
\hline QMGS & $\begin{array}{l}\rho \\
P \text { value }\end{array}$ & $\begin{array}{l}-0.532 \\
0.002^{1}\end{array}$ & $\begin{array}{l}-0.572 \\
0.001^{1}\end{array}$ & $\begin{array}{l}-0.480 \\
0.006^{1}\end{array}$ & NS \\
\hline
\end{tabular}

not applicable; 2mWT, 2-minute walk test; 6mWT, 6-minute walk test; FVC, forced vital capacity; MG-QoL 15T, myasthenia gravis-quality of life questionnaire-15 item assessment, Turkish version; MIP, maximal inspiratory pressure; NS, not significant; QMGS, quantitative myasthenia gravis score.

${ }^{1} \mathrm{P}=0.01$ after Bonferroni correction for multiple comparisons. 
normal healthy participants' values reported by Bohannon et $a .^{20}$ Although that study was not designed to obtain normal $6 \mathrm{mWT}$ values from patients with $\mathrm{MG}$, results from this study might be useful for future studies.

Primary and accessory inspiratory muscle involvement is essential for functional activities, and this relationship has been demonstrated in obstructive and restrictive diseases. ${ }^{33,34}$ We found a moderate correlation between MIP and 6mWT; this positive correlation indicates that a reduced exercise capacity in patients with MG may be related to inspiratory muscle weakness.

Anderson et al. ${ }^{14}$ reported that the $2 \mathrm{mWT}$ is a potential alternative to $6 \mathrm{mWT}$ in neuromuscular diseases (not included in MG) for describing walking capability. We also found high correlations between the $6 \mathrm{mWT}$ and 2mWT. Clinicians should choose $2 \mathrm{mWT}$ for patients who cannot complete the $6 \mathrm{mWT}$ because of fatigue or dyspnea. However, it should be taken into consideration that $2 \mathrm{mWT}$ had lower correlations with other parameters such as pulmonary function and strength, and it was not sensitive to fatigability.

Patients with generalized MG were included in this study, and predictive validity was tested between MGFA classes II and III. Classes I and IV/V were not included in our study. Moreover, classes II $\mathrm{a} / \mathrm{b}$ and III a/b were combined. The cutoff of values of timed walked tests are applicable to differentiate only between classes II and III. This was a limitation of our study because the results are not generalized for all patients with MG. To increase reproducibility, patients with ocular MG (class I) should be included in future studies. Class IV should also be included, but severe muscle weakness involvement may reduce reproducibility. The Borg scale was used for assessing fatigue perception. An additional fatigue scale could be used to assess fatigue in detail.

In conclusion, the $6 \mathrm{mWT}$ and $2 \mathrm{mWT}$ are performed easily in clinical settings and well tolerated in patients with MG. Both tests correlate moderately with disease specific outcomes and can be used as secondary efficacy measurements in clinical trials. However, the present study was carried out with a narrow spectrum of patients. Thus, the $6 \mathrm{mWT}$ and/or $2 \mathrm{mWT}$ may be integrated into routine assessments only in patients with mild and moderate generalized MG. However, additional studies that include different disability levels are required. Our results must also be confirmed by comprehensive studies that use cardiopulmonary exercise tests for criteria validation.

This study was presented at the National Cardiopulmonary Rehabilitation Congress, November 2017, Hacettepe University, Ankara, Turkey; and at the National Neurology Congress, November 2017, Antalya, Turkey.
Ethical Publication Statement: We confirm that we have read the Journal's position on issues involved in ethical publication and affirm that this report is consistent with those guidelines.

\section{REFERENCES}

1. Verschuuren IJ, Huijbers MG, Plomp IJ, Niks EH, Molenaar PC, Martinez-Martinez $\mathrm{P}$, et al. Pathophysiology of myasthenia gravis with antibodies to the acetylcholine receptor, muscle-specific kinase and low-density lipoprotein receptor-related protein 4. Autoimmun Rev 2013;12(9)918-923.

2. Gilhus NE, Verschuuren JJ. Myasthenia gravis: subgroup classification and therapeutic strategies. Lancet Neurol 2015;14(10):1023-1036.

3. Elsais A, Johansen B, Kerty E. Airway limitation and exercise intolerance in well-regulated myasthenia gravis patients. Acta Neurol Scand Suppl 2010;122(190):12-17.

4. Wolfsegger T, Stieglbauer K, Topakian R, Weiss E, Aichner F. Belastungsintensitäten für ein Ausdauer-und Krafttraining bei Patienten mit myasthenia gravis. Deutsche Zeitschrift fur Sportmedizin 2011; $62(5): 125$.

5. Feasson L, Camdessanché J-P, El Mhandi L, Calmels P, Millet G. Fatigue and neuromuscular diseases [in English, French]. Ann Réadap Méd Phys 2006;49(6):289-300, 375-384.

6. ATS Committee on Proficiency Standards for Clinical Pulmonary Function Laboratories. ATS statement: guidelines for the six-minute walk test. Am J Respir Crit Care Med 2002;166(1):111-117.

7. Zugck C, Krüger C, Dürr S, Gerber S, Haunstetter A, Hornig K, et al. Is the 6-minute walk test a reliable substitute for peak oxygen uptake in patients with dilated cardiomyopathy? Eur Heart J 2000;21(7):540-549.

8. Hamilton DM, Haennel R. Validity and reliability of the 6-minute walk test in a cardiac rehabilitation population. J Cardiopulm Rehabil 2000; 20(3):156-164.

9. Savci S, Inal-Ince D, Arikan H, Guclu-Gunduz A, Cetisli-Korkmaz N, Armutlu K, et al. Six-minute walk distance as a measure of functional exercise capacity in multiple sclerosis. Disabil Rehabil 2005;27(22): 1365-1371.

10. du Bois RM, Weycker D, Albera C, Bradford WZ, Costabel U, Kartashov A, et al. Six-minute-walk test in idiopathic pulmonary fibrosis: test validation and minimal clinically important difference. Am J Respir Crit Care Med 2011;183(9):1231.

11. Gijbels D, Eijnde B, Feys P. Comparison of the 2-and 6-minute walk test in multiple sclerosis. Mult Scler 2011;17(10):1269-1272.

12. Roitman JL, Kalra S. Reliability, validity, and responsiveness of a 2-min walk test to assess exercise capacity of COPD patients. J Cardiopulm Rehabil 2007;27(2):116.

13. Brooks D, Parsons J, Tran D, Jeng B, Gorczyca B, Newton J, et al. The two-minute walk test as a measure of functional capacity in cardiac surgery patients. Arch Phys Med Rehabil 2004;85(9):1525-1530.

14. Andersen LK, Knak KL, Witting N, Vissing J. Two-and 6-minute walk tests assess walking capability equally in neuromuscular diseases. Neurology 2016;86(5):442-445.

15. Barohn RJ, McIntire D, Herbelin L, Wolfe GI, Nations S, Bryan WW. Reliability testing of the quantitative myasthenia gravis score. Ann N Y Acad Sci 1998;841(1):769-772.

16. Laszlo G. European standards for lung function testing: 1993 update. Thorax 1993;48(9):873

17. Hamnegard C, Wragg S, Kyroussis D, Aquilina R, Moxham J, Green M. Portable measurement of maximum mouth pressures. Eur Respir J 1994;7(2):398-401.

18. Black LF, Hyatt RE. Maximal respiratory pressures: normal values and relationship to age and sex. Am Rev Respir Dis 1969;99(5):696-702.

19. Evans JA, Whitelaw WA. The assessment of maximal respiratory mouth pressures in adults. Respir Care 2009;54(10):1348-1359.

20. Bohannon RW, Wang Y-C, Gershon RC. Two-minute walk test performance by adults 18 to 85 years: normative values, reliability, and responsiveness. Arch Phys Med Rehabil 2015;96(3):472-477.

21. Enright PL, Sherrill DL. Reference equations for the six-minute walk in healthy adults. Am J Respir Crit Care Med 1998;158(5):1384-1387.

22. Burns TM, Sadjadi R, Utsugisawa K, Gwathmey KG, Joshi A, Jones S, et al. International clinimetric evaluation of the MG-QOL15, resulting in slight revision and subsequent validation of the MG-QOL15r. Muscle Nerve 2016;54(6):1015-1022.

23. Taşcilar NF, Saraçli Ö, Kurcer MA, Ankarali H, Emre U. Reliability and validity of the Turkish version of myasthenia gravis-quality of life questionnaire-15 item. Turk J Med Sci 2016;46(4):1107-1113.

24. Mokkink LB, Terwee CB, Knol DL, Stratford PW, Alonso J, Patrick DL, et al. The COSMIN checklist for evaluating the methodological quality of studies on measurement properties: a clarification of its content BMC Med Res Methodol 2010;10(1):22.

25. Dancey CP, Reidy J. Statistics without maths for psychology. London, United Kingdom: Pearson Education; 2007.

26. Faul F, Erdfelder E, Lang A-G, Buchner A. G* Power 3: a flexible statistical power analysis program for the social, behavioral, and biomedical sciences. Behav Res Methods 2007;39(2):175-191. 
27. Gibbons WJ, Fruchter N, Sloan S, Levy RD. Reference values for a multiple repetition 6 -minute walk test in healthy adults older than 20 years. J Cardiopulm Rehabil 2001;21 (2):87-93.

28. Crescimanno G, Modica R, Mauro RL, Musumeci O, Toscano A, Marrone $\mathrm{O}$. Role of the cardio-pulmonary exercise test and six-minute walking test in the evaluation of exercise performance in patients with late-onset Pompe disease. Neuromuscul Disord 2015;25(7):542-547.

29. McDonald CM, Henricson EK, Abresch RT, Florence J, Eagle M, Gappmaier E, et al. The 6-minute walk test and other clinical endpoints in duchenne muscular dystrophy: reliability, concurrent validity, and minimal clinically important differences from a multicenter study. Muscle Nerve 2013;48(3): 357-368.

30. Troosters T, Gosselink R, Decramer M. Six minute walking distance in healthy elderly subjects. Eur Respir J 1999;14(2):270-274.
31. Casanova C, Celli B, Barria P, Casas A, Cote C, De Torres J, et al. The 6-min walk distance in healthy subjects: reference standards from seven countries. Eur Respir J 2011;37(1):150-156.

32. Camarri B, Eastwood PR, Cecins NM, Thompson PJ, Jenkins S. Six minute walk distance in healthy subjects aged 55-75 years. Respir Med 2006;100(4):658-665.

33. Wijkstra P, TenVergert E, van der Mark T, Postma D, Van Altena R, Kraan J, et al. Relation of lung function, maximal inspiratory pressure, dyspnoea, and quality of life with exercise capacity in patients with chronic obstructive pulmonary disease. Thorax 1994;49(5): $468-472$.

34. Dourado VZ, de Oliveira Antunes LC, Tanni SE, de Paiva SAR, Padovani CR, Godoy I. Relationship of upper-limb and thoracic muscle strength to 6-min walk distance in COPD patients. Chest 2006;129(3): $551-557$. 